\title{
Good results with minimally invasive unicompartmental knee resurfacing after 10-year follow-up
}

\author{
Martin H. Redish ${ }^{1}$. Peter Fennema ${ }^{2}$
}

Received: 9 August 2017 / Accepted: 12 November 2017 / Published online: 22 November 2017

(c) The Author(s) 2017. This article is an open access publication

\begin{abstract}
The current study was designed to determine (1) 10-year implant survival and (2) patient's self-reported functional outcome in a single surgeon's consecutive cohort of patients who had undergone minimally invasive unicondylar resurfacing with a modified cementation technique utilizing a cobalt-chromium femur/inlaid all-PE tibia, fixed-bearing unicompartmental prosthesis. We included 344 consecutive patients (361 knees) who had received the study device between January 2002 and December 2005 in this retrospective study. After 10 years, 78 patients (78 knees) had died, 59 (59 knees) were lost to follow-up and four (four knees) did not participate. Thirteen knees (11 patients) were revised after a mean of $5.8 \pm 1.9$ years. Hence, the study population at follow-up comprised 192 patients (207 knees). Ten-year implant survival was 94.6\% (95\% confidence interval, 90.9-96.8\%). The Forgotten Joint Score and Oxford Knee Score were 68.9 \pm 28.9 and 39 \pm 9.1, respectively. Excellent survivorship and clinical outcomes were obtained with UKA with an inlaid all-PE tibia with a modified cementation technique.
\end{abstract}

Keywords Osteoarthritis, knee $\cdot$ Arthroplasty, replacement, knee $\cdot$ Unicompartmental knee replacement $\cdot$ Cementation · Survival analysis

\section{Introduction}

Total knee arthroplasty (TKA) achieves excellent outcomes on a range of measures. However, patients may experience significant limitations, such as impaired functional activity [1], and residual pain [2]. Unicompartmental knee arthroplasty (UKA) is a less-invasive procedure, resulting in faster rehabilitation, greater preservation of bone stock, reduced blood loss, and a lower risk of infection in comparison with TKA [3-7]. Furthermore, knee kinematics following UKA has been reported to be closer to those of the native knee than with TKA [8-10]. As such, UKA may represent a valuable alternative to TKA for patients who do not need the more invasive procedure [11]. Nevertheless, $50 \%$ of conversions from UKA to TKA have significant bone defects, and

Martin H. Redish

mredish@epbfi.com

1 Parkridge Bone and Joint, 2205 McCallie Ave. Suite 102, Chattanooga, TN 37404, USA

2 AMR Advanced Medical Research GmbH, Hofenstrasse 89b, 8708 Männedorf, Switzerland stemmed implants and/or augments are required in up to $80 \%$ of cases [12-15].

The Repicci II (Biomet, Inc, Warsaw, IN, USA) is a cobalt-chromium femur/inlaid all-polyethylene tibia, fixedbearing unicompartmental prosthesis that is used with a minimally invasive surgical (MIS) technique. In contrast to the commonly used resection UKA, this resurfacing design maintains all the bone stock required for conversion to primary TKA [16]. The popularity of the Repicci prosthesis has waned recently due to variable survivorship outcomes, the need for a freehand bone sculpting, and fears over subsidence of the tibial inlay. While good short- and mid-term functional results have been reported [17, 18], and a study by the device inventor reported low revision rates after 8 years [19], one investigation [18] reported lower mid-term survivorship and rates of revision than those recorded for other UKA systems [20-22]. However, the longevity of UKA is highly dependent on the surgical technique, as well as on implant position and alignment [23, 24].

The study device was adopted in our clinic with a modified cementation technique. We aimed to assess whether this procedure is successful in our heterogeneous patient population. In patients under 60 , the less a UKA compromises any 
future revisions is important. If avoiding revision TKA is thought of as an endpoint to avoid, if successful, this technique when utilized in the algorithm of care, may put off primary TKA for a significant amount of time. In patients over 75 , if this procedure is safe, it may prevent elderly patients from the arduous recovery of TKA.

\section{Materials and methods}

We retrospectively recruited consecutive patients with isolated medial or lateral osteoarthritis who underwent cemented unicondylar resurfacing with the Repicci II UKA system between January 2002 and December 2005.

All patients who had received the Repicci II UKA system implant from the first author were eligible. Patients in the study all had Kellgren-Lawrence Grade 4 changes on the affected side with no more than maximum $2 \mathrm{~mm}$ joint space on weight-bearing anteroposterior radiographs. Medical comorbidities were across the spectrum, with this procedure often favoured over TKA in the presence of more severe medical conditions due to its safety [25]. Activity levels of patients factored into choice of UKA versus TKA, with UKA favoured for those wanting more active lifestyles (such as hiking and farming). Patients ineligible for resurfacing UKA were those who had inflammatory diseases or significant involvement of the contralateral compartment, as detected at intraoperative arthroscopic examination. Patients with isolated lateral cartilage lesions, particularly those adjacent to the femoral notch, were included; patients with diffuse weight-bearing lesions or with symptomatic patellofemoral osteoarthritis underwent TKA. The decision is also affected by the patient's age, weight and life expectancy, as well as their personal preference.

Patients were recruited consecutively from the institution's surgery list, beginning with those operated on first. To minimize attrition, at least three attempts were made to contact each patient, with those who did not respond to a telephone call contacted at least twice by mail. In addition, the patient's general practitioner was contacted, if known. The patients were informed by the investigator as to the purpose of the study, and invited to participate. The records of patients who consented to take part in the study were reviewed, and patient variables, including baseline age, sex and body mass index (BMI), were extracted. The Forgotten Joint Score (FJS) [26] and the Oxford Knee Score [27] questionnaires were mailed to the patients. The FJS is a 12 -item patient-reported outcome questionnaire specifically designed to identify the awareness of the replaced knee or hip joint during various daily life activities. The score ranges from 0 to 100 [26]. A high score indicates good outcome, i.e. a high degree of "forgetting" the artificial joint. The Oxford Knee Score (OKS) is a 12-item patient-reported outcome questionnaire that was developed to assess function and pain after knee arthroplasty surgery. The score ranges from 0 (worst outcome) to 48 (best outcome) [27]. Each subject was informed of their right to refuse to participate or to withdraw their consent at any time. IRB approval was obtained prior to study commencement.

The primary endpoint was implant survival, with device explantation for any reason as the event of interest. For patients who are alive and unrevised, secondary endpoints were the FJS and the Oxford Knee Score, while those for patients who had undergone revision were the date and reason for revision, and the components that were explanted. For patients who had died, the date of death was recorded. For patients lost to follow-up, the last time-point that the prosthesis was known to be in situ was obtained. Patients who experienced a revision and subsequently died were included as revised patients. All clinical data was verified, and only depersonalized data was recorded.

All patients underwent a modification of the Repicci technique [16]. The standard operating table was turned backwards, with the unaffected leg placed in a stirrup holder and the affected leg left free. For medial knees, an arthroscopic post was placed laterally to allow valgus stress and lifting of the leg to obtain more flexion, if needed. For lateral knees, an arthroscopic leg holder was placed.

A brief arthroscopic examination was performed to confirm whether to perform UKA or TKA. If it was UKA, the incision was made from the superior pole of the patella to just above the tibial tubercle (Fig. 1). The capsule was incised in line with the skin incision and extended proximally just into the muscular area. A small portion of the patella edge was resected. The knee was exposed and held in a neutral position at $100^{\circ}$ of flexion. Using a saw blade, an $8-12-\mathrm{mm}$ posterior femoral condyle cut was made in line with the posterior shaft. The cut edge was rounded off with a bur and the meniscus removed entirely. For medial replacement, with the knee in flexion and valgus, a small Hohman retractor was placed over the medial edge of the tibial plateau, and the tibial inlay was prepared using round and cylindrical burrs. The inlay was placed as far medial as possible, leaving a very thin rim on the medial side.

The tibial trial was placed into the defect. The objective was a neutral position ( $3^{\circ}$ varus inclination), with the medial edge sitting $2-4 \mathrm{~mm}$ proud, depending on the degree of varus inclination of the patient's tibial plateau. Femoral preparation was performed freehand, with burrs down to the subchondral bone, keeping the femoral component position laterally, close to the femoral notch (Fig. 2a). The hole was created using a standard cutting jig with a drill, while a small saw and 2-mm wire-passing burr was used for the slot. The trial components were then placed to confirm the proper fit and ensure that the articulating components maintained contact through the full range of motion. Coronal plane limb 


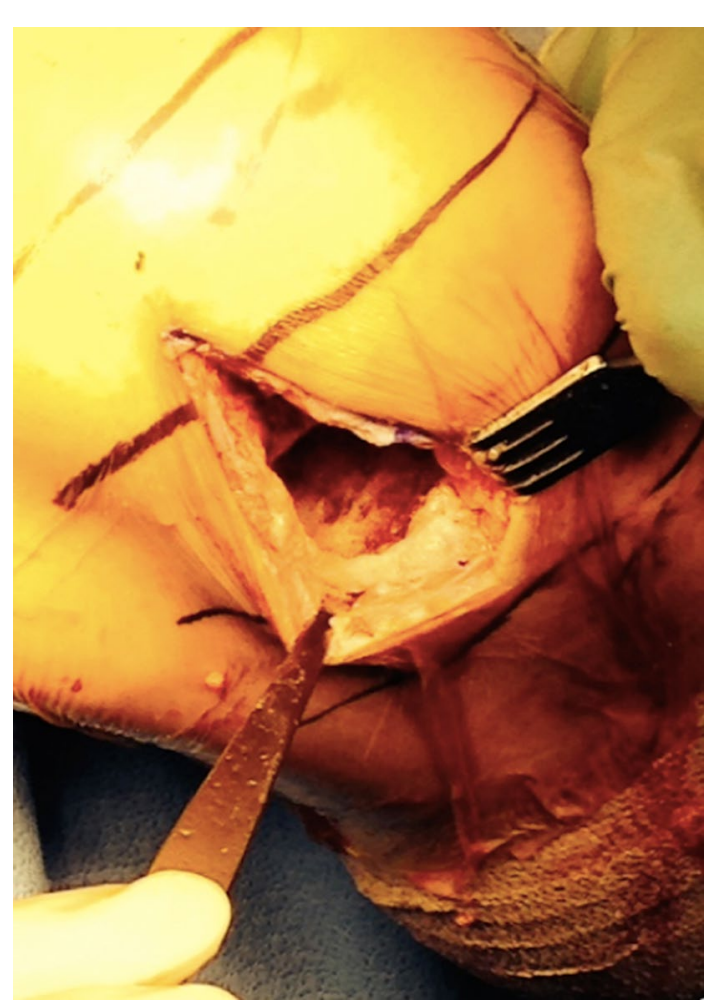

Fig. 1 Surgical incision from the superior pole of the patella to just above the tibial tubercle

alignment was checked to avoid overcorrection into valgus. The trials were removed and high-pressure pulse lavage performed, on the tibial inlay preparation. This is done by a malleable frazier suction bent to a right angle at the end and inserted into a standard pulse lavage device. This enables deeper cement penetration into the tibia by more thoroughly cleaning out marrow contents from the subchondral bone [28]. Low viscosity bone cement (CMW 3, DePuy, Warsaw, IN) was introduced into the tibial defect as soon as it became workable to allow for deep penetration. The $6.5-8.5 \mathrm{~mm}$ all-polyethylene inlayed tibial component was placed on the sclerotic subchondral bone no deeper than 4-5 $\mathrm{mm}$ from the joint surface, with direct firm pressure to fully seat the component. Then, the femoral component was carefully cemented, and femoral osteophytes removed. The tissues were infiltrated with Marcaine plus epinephrine. The knee was then irrigated and closed over a $1 / 8$ in. standard hemovac drain.

For lateral resurfacings, the posterior femoral cut averaged $6 \mathrm{~mm}$ in thickness. The tibial component was internally rotated and contact areas with the femur carefully marked throughout flexion and extension. Placement of the femoral component corresponded with these markings.

Patients were ambulated the day of surgery with weight bearing as tolerated, and discharged the following day after removal of the drain. Narcotics were discontinued after 1 week. Aspirin was prescribed as deep vein thrombosis prophylaxis for 1 month postoperatively.

Patient demographics and baseline characteristics, as well as outcome data, were recorded. Kaplan-Meier (KM) analysis was used to determine implant survival, including
Fig. 2 Positioning of the femoral component laterally and close to the femoral notch. Figure 4a shows correct femoral component placement; Fig. 4b shows incorrect positioning (a)

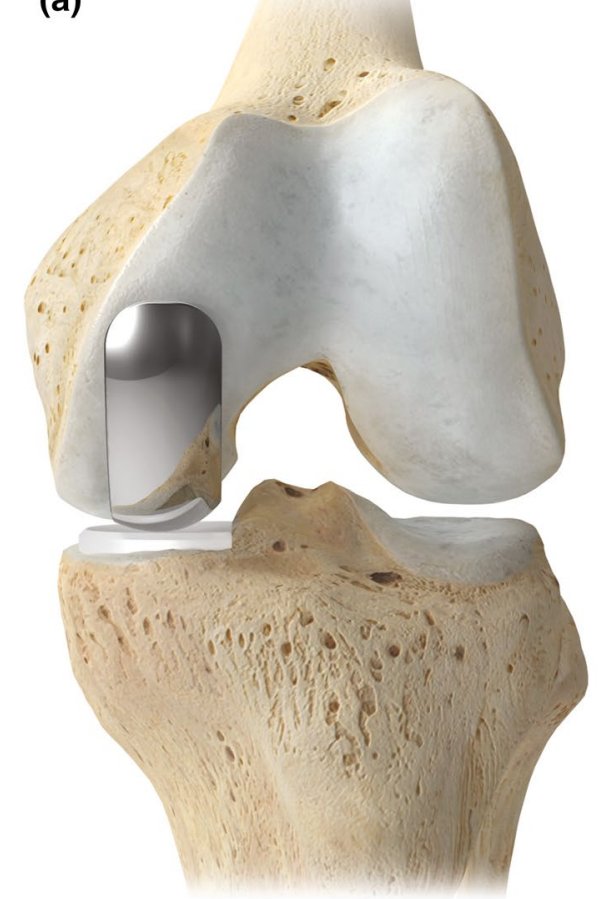

(b)

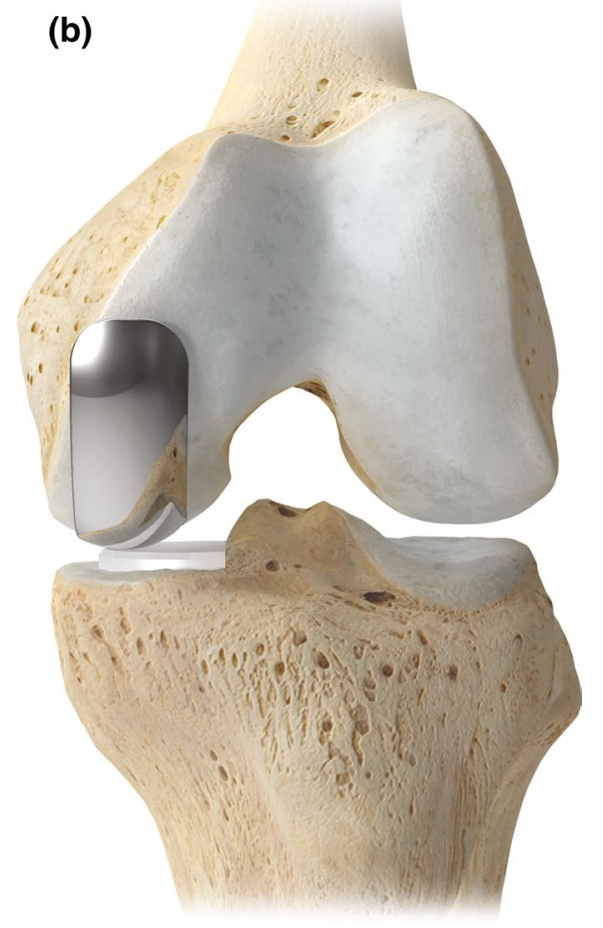


95\% confidence intervals (CI), with revision of any implant component as the endpoint. Multiple linear regression was also performed to determine the influence of joint covariates on the estimates. The continuous predictor variables age and BMI were categorized into four and five levels, respectively. Patient ages between 55 and 65 years and a BMI between 25 and $30 \mathrm{~kg} / \mathrm{m}^{2}$ were chosen as the reference levels, as they were the most prevalent in the study cohort. $p<0.05$ was considered statistically significant. Two-tailed tests were used throughout, with Stata/SE, version 12.1 (Stata Corp, College Station, TX, USA) used for all analyses.

\section{Results}

Three hundred and ninety-three consecutive knees were eligible for UKA. Of those, 32 knees scheduled to undergo UKA were switched to TKA following intraoperative arthroscopic examination, leaving 361 knees (344 patients) for inclusion in the study. The mean age at surgery was $70.5 \pm 13.1$ years, the mean BMI was $30.9 \pm 6.1 \mathrm{~kg} / \mathrm{m}^{2}$, and 188 patients $(54.7 \%)$ were female. Three hundred forty knees were treated for medial and 21 for lateral compartment osteoarthritis.

All patients were mobilized immediately following surgery and discharged on postoperative day one. Perioperatively, one superficial infection and one hemarthrosis were noted.

At follow-up, 78 (22.7\%) patients (78 knees [21.6\%]) had died due to causes unrelated to the procedure and 59 (17.2\%) patients (59 [16.3\%] knees) were considered lost to follow-up. Four (1.2\%) patients (4 [1.1\%] knees) did not participate due to being in a hospice or being incapacitated. Eleven (3.2\%) patients (13 [3.6\%] knees) underwent revision surgery after a mean of $5.8 \pm 1.9$ years (Table 1$)$. A standard primary TKA with minimum polyethylene insert thickness was used for all revisions. Of the revisions for unexplained medial pain $(n=7)$, five improved after revision, whereas two did not. Ten-year implant survival on Kaplan-Meier analysis was $94.6 \%$ (95\% CI, 90.9-96.8\%) (Fig. 3).

One hundred and ninety-two patients (207 knees) agreed to follow-up assessment, after a mean follow-up of $10.8 \pm 1.1$ years. All patients completed the clinical questionnaires. The mean FJS at follow-up was $68.9 \pm 28.9$, and the mean OKS was $39.5 \pm 9.1$. Preoperative and postoperative radiographs of a typical patient with a Repicci II knee are shown in Fig. 4.

The results of the multiple linear regression analysis are shown in Table 2 . The only statistically significant difference was that patients with a BMI $>40 \mathrm{~kg} / \mathrm{m}^{2}$ had significantly lower FJS and OKS scores than those with a lower BMI $(p=0.009)$.
Table 1 Overview of revisions with exchange of components

\begin{tabular}{lllll}
\hline Patient & Gender & $\begin{array}{l}\text { Age at sur- } \\
\text { gery (years) }\end{array}$ & $\begin{array}{l}\text { Time of revi- } \\
\text { sion (years) }\end{array}$ & Reason for revision \\
\hline 1 & Female & 63.7 & 5.3 & Unexplained pain \\
2 & Male & 65.4 & 5.6 & Unexplained pain \\
3 & Male & 69.7 & 7.3 & Traumatic fracture \\
4 & Female & 65.8 & 7.2 & Progression \\
5 & Female & 65.6 & 7.4 & Progression \\
6 & Female & 60.0 & 5.0 & Femoral loosening \\
7 & Male & 58.4 & 3.6 & Tibial component \\
& & & & loosening/subsid- \\
& & & & ence \\
8 & Female & 59.6 & 8.4 & Unexplained pain \\
9 & Male & 64.4 & 3.6 & Gouty arthritis \\
10 & Female & 61.6 & 4.4 & Unexplained pain \\
11 & Female & 63.4 & 3.6 & Unexplained pain \\
12 & Female & 62.7 & 4.3 & Unexplained pain \\
13 & Female & 60.9 & 9.1 & Unexplained pain \\
\hline
\end{tabular}

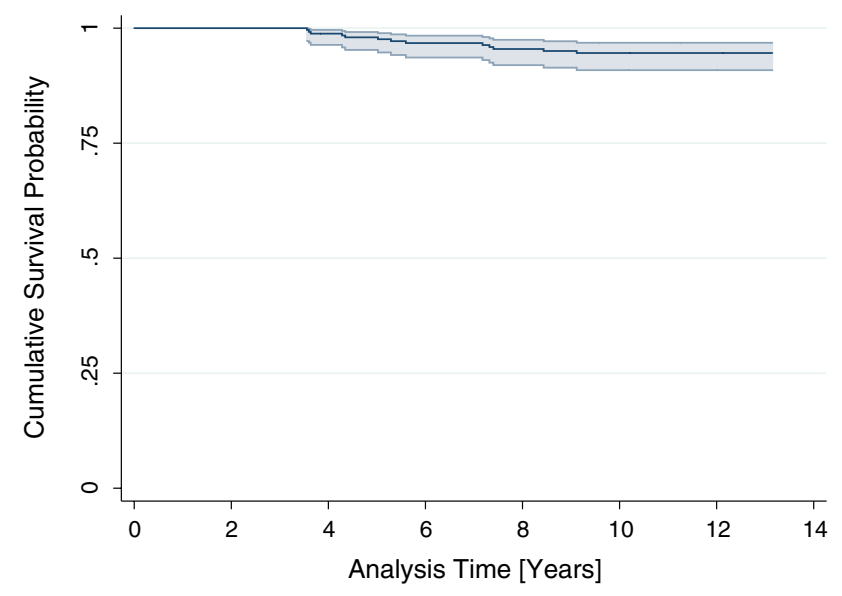

Fig. 3 Kaplan-Meier survival plot of revision for any reason

\section{Discussion}

Our results demonstrate that good survival and clinical outcomes can be achieved using a resurfacing UKA design with an inlay tibial component, implanted through a minimally invasive surgical technique. In the few UKAs that required conversion to TKA, no stems or augments were needed.

The Australian Orthopaedic Association National Joint Replacement Registry has reported 10-year survival rates of $94.4 \%$ for TKA and of $84.9 \%$ for UKA in primary OA [29]. The 10-year survival recorded in our series is comparable to those of previous publications. In a retrospective analysis of 136 UKAs using the Repicci system, Romanowski and Repicci [19] reported a revision rate of 
(a)

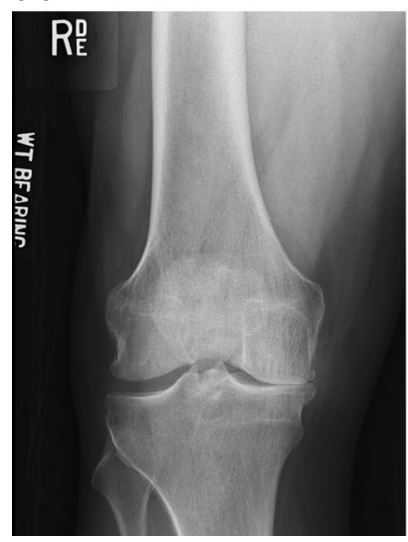

(b)

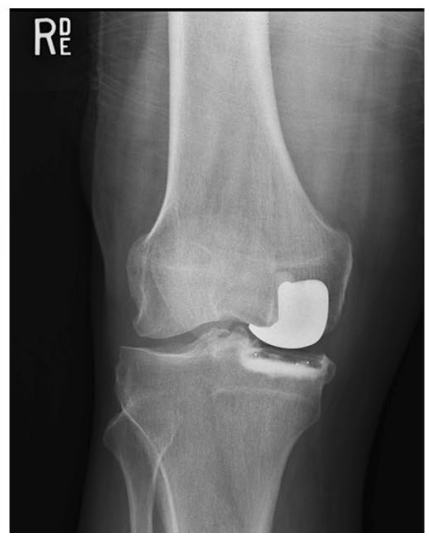

(c)

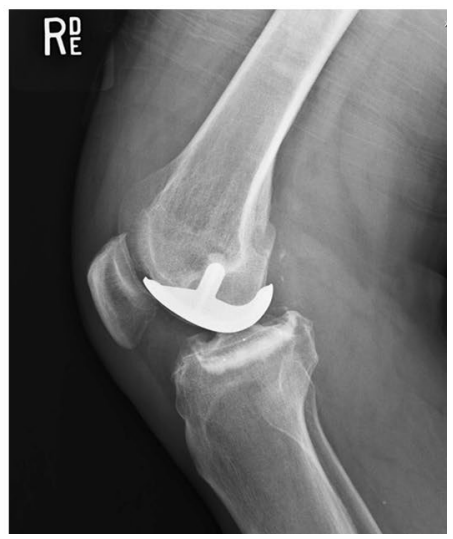

Fig. 4 a 58-year old male patient with presenting with medial pain. Preoperative anteroposterior radiograph. b Postoperative anteroposterior and lateral radiographs. Postoperative radiographs show correct implant position. $\mathbf{c}$ Lateral radiograph

Table 2 Multiple linear regression analysis

\begin{tabular}{|c|c|c|c|c|c|c|}
\hline & \multicolumn{3}{|c|}{ Forgotten Joint Score } & \multicolumn{3}{|c|}{ Oxford Knee Score } \\
\hline & Adjusted mean & $95 \% \mathrm{CI}$ & $p$ value & Adjusted mean & $95 \% \mathrm{CI}$ & $p$ value \\
\hline \multicolumn{7}{|c|}{ Age (years) } \\
\hline$<55$ & 60.7 & $49.1-72.3$ & 0.290 & 39.0 & $35.3-42.6$ & 0.293 \\
\hline $55-65$ & 66.8 (reference) & $56.9-76.7$ & - & 39.8 (reference) & $36.7-42.9$ & - \\
\hline $65-75$ & 69.5 & $60.3-78.6$ & 0.582 & 40.4 & $37.5-43.3$ & 0.968 \\
\hline$>75$ & 76.9 & $64.4-89.4$ & 0.136 & 41.6 & $37.7-45.6$ & 0.003 \\
\hline \multicolumn{7}{|c|}{$\operatorname{BMI}\left(\mathrm{kg} / \mathrm{m}^{2}\right)$} \\
\hline$<5$ & 69.3 & $55.5-83.1$ & 0.708 & 42.1 & $37.7-46.4$ & 0.293 \\
\hline $25-30$ & 66.8 (reference) & $56.9-76.7$ & - & 39.8 (reference) & $36.7-42.9$ & - \\
\hline $30-35$ & 67.8 & $58.5-77.0$ & 0.846 & 37.8 & $35.0-40.8$ & 0.223 \\
\hline $35-40$ & 72.0 & $60.1-83.8$ & 0.436 & 40.0 & $36.1-43.6$ & 0.968 \\
\hline$>40$ & 48.8 & $36.0-60.9$ & 0.009 & 33.3 & $29.3-37.2$ & 0.003 \\
\hline Male & 71.0 & $61.2-80.8$ & 0.288 & 40.8 & $37.7-43.9$ & 0.419 \\
\hline
\end{tabular}

$B M I$ body mass index, $C I$ confidence interval
$7 \%$ at 8 years, while Kohan et al. [30] reported 10 year survival of $91.6 \%$. Fuchs et al. [17] described encouraging short-term outcomes with the Repicci system in 379 UKAs at 40 weeks follow-up, with good clinical outcomes and $95 \%$ of patients subjectively satisfied with the procedure. In contrast, O'Donnell et al. prospectively followed 100 patients who underwent 114 UKAs with the study system under a short-stay MIS protocol. With 22 patients revised a mean of 6.2 years later, the 9-year survival of the prosthesis was estimated at $78 \%$ [18].

Our study design does not allow an understanding of the causes or reasons for the good outcome observed in our study. In the authors' opinion, there are several potential factors that have contributed to the favorable outcome obtained in our patient series. First, we believe that diagnostic arthroscopy at the time of index surgery is an essential step to reduce the rate of future conversion to TKA due to disease progression in the contralateral compartment. It was decided to perform TKA instead of UKA in 10\% of the study population following arthroscopy. Second, the authors feel that the cementation technique employed in this patient series may have contributed to the implant's longevity.

Third, by resecting 8-12 $\mathrm{mm}$ of the posterior femoral condyle, we have allowed enough space to more accurately create the bed for the tibial inlay and removal of excess cement posteriorly. Increasing the flexion gap in UKA has not been shown to be of clinical relevance, possibly due to the cruciate ligaments remaining intact [31]. Braun et al. [32] have shown that resection of the entire posteromedial femoral condyle in athletes to use as bone grafts does not lead to donor site complications, including flexion instability.

Some minor changes to the surgical technique described have been recently implemented. A drain is not deemed necessary any longer [33], tranexamic acid is administered to 
reduce blood loss $[34,35]$ and the majority of procedures are performed as outpatients. For medial UKA, none of the patella is resected. In the current series, only one single case of tibial subsidence was observed and therefore no significant association between morbid obesity (BMI > 40) and early loosening was found. Based on the poorer clinical outcome, we nevertheless nowadays are reluctant to use the device in this particular patient population.

In our series, the study system was associated with good clinical outcomes on both the OKS and FJS. OKS compared favorably with 6-month results for TKA from the National Joint Registry for England and Wales [36] and the New Zealand Joint Registry [37]. The FJS in our UKA cohort was significantly higher than that reported in a cohort of TKA patients by Behrend et al. [26], although still lower than their group of healthy controls (Table 3). Our findings coincide with those from Zuiderbaan et al. [38], who found significantly higher FJS values in UKA patients $(74.3 \pm 24.8)$ than in TKA patients $(59.8 \pm 31.5)$, at a follow-up time of 2 years. Notably, patients with a BMI $>40 \mathrm{~kg} / \mathrm{m}^{2}$ had lower FJS scores in our series. While our results are highly encouraging, we acknowledge that further studies are required to confirm that they reflect improved outcome after resurfacing UKA. We feel that the FJS is an important method for assessing patient outcome, as the patient's ability to forget their artificial joint in everyday life could be regarded as the ultimate goal in joint arthroplasty [26]. Our data suggest that resurfacing UKA appears to accomplish this objective better than primary TKA.

There are several limitations to our study. The study did not include radiographic assessment at follow-up. A relatively large proportion of patients was lost to follow-up. However, the rate of attrition is not uncommonly high for a retrospective study of this length. Another limitation is that all of the procedures were performed by a single surgeon in a single institution. Consequently, the findings are not readily generalizable. In addition, our results were not compared with those for other UKA systems, or with those achieved with TKA. We did not collect baseline data; hence, we were unable to assess the postoperative improvement in

Table 3 FJS Results compared with results from the literature [26]

\begin{tabular}{lll}
\hline & Sex & Mean (SD) \\
\hline Our values & Male & $71.6(28.5)$ \\
\multirow{2}{*}{ THA } & Female & $66.6(29.1)$ \\
& Male & $63.8(29.2)$ \\
TKA & Female & $54.7(32.1)$ \\
& Male & $56.5(30.1)$ \\
Healthy controls & Female & $45.4(28.0)$ \\
& Male & $86.6(17.0)$ \\
& Female & $79.3(23.2)$ \\
\hline
\end{tabular}

OKS scores. We did not document the grade of opposite compartment degenerative disease, and such factors cannot be taken into account when assessing the data. Based on the joint impact of these limitations, inferences from this study should be drawn with caution. Nevertheless, our series represents the largest cohort with long-term follow-up available for this system outside of the inventor's clinic.

Our long-term follow-up study indicates that, with the described surgical technique, excellent survivorship and clinical outcomes can be obtained with the Repicci II system. Further studies are required to confirm our findings.

\section{Compliance with ethical standards}

Conflict of interest Dr. Redish is a paid consultant for Zimmer Biomet. Dr. Fennema is a paid consultant for Zimmer Biomet.

Open Access This article is distributed under the terms of the Creative Commons Attribution 4.0 International License (http://creativecommons.org/licenses/by/4.0/), which permits unrestricted use, distribution, and reproduction in any medium, provided you give appropriate credit to the original author(s) and the source, provide a link to the Creative Commons license, and indicate if changes were made.

\section{References}

1. Noble PC, Gordon MJ, Weiss JM, Reddix RN, Conditt MA, Mathis KB (2005) Does total knee replacement restore normal knee function? Clin Orthop Relat Res 431:157-165

2. Nashi N, Hong CC, Krishna L (2015) Residual knee pain and functional outcome following total knee arthroplasty in osteoarthritic patients. Knee Surg Sports Traumatol Arthrosc 23(6):1841-1847

3. Argenson JN, Chevrol-Benkeddache Y, Aubaniac JM (2002) Modern unicompartmental knee arthroplasty with cement: a three to ten-year follow-up study. J Bone Jt Surg Am 84-A(12):2235-2239

4. Engh GA (2002) Orthopaedic crossfire-can we justify unicondylar arthroplasty as a temporizing procedure? In the affirmative. J Arthroplasty 17(4 Suppl 1):54-55

5. Rougraff BT, Heck DA, Gibson AE (1991) A comparison of tricompartmental and unicompartmental arthroplasty for the treatment of gonarthrosis. Clin Orthop Relat Res 273:157-164

6. Knutson K, Lindstrand A, Lidgren L (1986) Survival of knee arthroplasties. A nation-wide multicentre investigation of 8000 cases. J Bone Jt Surg Br 68(5):795-803

7. Iacono F, Raspugli GF, Akkawi I, Bruni D, Filardo G, Budeyri A, Bragonzoni L, Presti ML, Bonanzinga T, Marcacci M (2016) Unicompartmental knee arthroplasty in patients over 75 years: A definitive solution? Arch Orthop Trauma Surg 136(1):117-123

8. Akizuki S, Mueller JK, Horiuchi H, Matsunaga D, Shibakawa A, Komistek RD (2009) In vivo determination of kinematics for subjects having a Zimmer Unicompartmental High Flex Knee System. J Arthroplasty 24(6):963-971

9. Jung MC, Chung JY, Son KH, Wang H, Hwang J, Kim JJ, Kim $\mathrm{JH}$, Min BH (2014) Difference in knee rotation between total and unicompartmental knee arthroplasties during stair climbing. Knee Surg Sports Traumatol Arthrosc 22(8):1879-1886

10. Heyse TJ, El-Zayat BF, De Corte R, Chevalier Y, Scheys L, Innocenti B, Fuchs-Winkelmann S, Labey L (2014) UKA closely 
preserves natural knee kinematics in vitro. Knee Surg Sports Traumatol Arthrosc 22(8):1902-1910

11. Heyse TJ, Khefacha A, Peersman G, Cartier P (2012) Survivorship of UKA in the middle-aged. Knee 19(5):585-591

12. Wynn Jones H, Chan W, Harrison T, Smith TO, Masonda P, Walton NP (2012) Revision of medial Oxford unicompartmental knee replacement to a total knee replacement: similar to a primary? Knee 19(4):339-343

13. Chou DT, Swamy GN, Lewis JR, Badhe NP (2012) Revision of failed unicompartmental knee replacement to total knee replacement. Knee 19(4):356-359

14. Barrett WP, Scott RD (1987) Revision of failed unicondylar unicompartmental knee arthroplasty. J Bone Jt Surg Am 69(9):1328-1335

15. Paredes EB, Sanchez PB, Toledano DS, Gonzalez AIP, Perez SF, de Bobadilla GDF (2017) Total knee arthroplasty after failed unicompartmental knee arthroplasty. Clinical results, radiologic findings, and technical tips. J Arthroplasty 32(1):193-196

16. Repicci J, Hartman JF (2006) Minimally invasive surgery for unicondylar knee arthroplasty: the bone-sparing technique. In: Scuderi GR, Tria AJ, Berger RA (eds) MIS techniques in orthopedics. Springer, New York, pp 193-213

17. Fuchs S, Strosche H, Tinius W, Gierse H, Gebhardt U (2005) Preliminary remarks on a prospective multicenter study of the Repicci minimally invasive unicondylar knee replacement. Knee Surg Sports Traumatol Arthrosc 13(8):670-676

18. O'Donnell T, Neil MJ (2010) The Repicci II(R) unicondylar knee arthroplasty: 9-year survivorship and function. Clin Orthop Relat Res 468(11):3094-3102

19. Romanowski MR, Repicci JA (2002) Minimally invasive unicondylar arthroplasty: eight-year follow-up. J Knee Surg 15(1):17-22

20. Vasso M, Del Regno C, Perisano C, D’Amelio A, Corona K, Schiavone Panni A (2015) Unicompartmental knee arthroplasty is effective: ten year results. Int Orthop 39(12):2341-2346

21. Price AJ, Waite JC, Svard U (2005) Long-term clinical results of the medial Oxford unicompartmental knee arthroplasty. Clin Orthop Relat Res 435:171-180

22. Heyse T, Khefacha A, Peersman G, Cartier P (2012) Survivorship of UKA in the middle-aged. Knee 19(5):585-591

23. Chatellard R, Sauleau V, Colmar M, Robert H, Raynaud G, Brilhault J, Societe d'Orthopedie et de Traumatologie de $1 O$ (2013) Medial unicompartmental knee arthroplasty: does tibial component position influence clinical outcomes and arthroplasty survival? Orthop Traumatol Surg Res 99(4 Suppl):S219-225

24. Epinette JA, Brunschweiler B, Mertl P, Mole D, Cazenave A, French Society for H, Knee (2012) Unicompartmental knee arthroplasty modes of failure: wear is not the main reason for failure: a multicentre study of 418 failed knees. Orthop Traumatol Surg Res 98(6 Suppl):S124-130

25. Liddle AD, Judge A, Pandit H, Murray DW (2014) Adverse outcomes after total and unicompartmental knee replacement in 101,330 matched patients: a study of data from the National Joint Registry for England and Wales. Lancet 18(314):1437-1445
26. Behrend H, Giesinger K, Giesinger JM, Kuster MS (2012) The "forgotten joint" as the ultimate goal in joint arthroplasty: validation of a new patient-reported outcome measure. J Arthroplasty 27(3):430-436 (e431)

27. Murray D, Fitzpatrick R, Rogers K, Pandit H, Beard D, Carr A, Dawson J (2007) The use of the Oxford hip and knee scores. J Bone Jt Surg Br 89(8):1010-1014

28. Thompson M, Conditt M, Otto J, Abassi A, Redish M (2010) The importance of a good cement mantle with an all-poly inlay UKA. Poster No. 2121. In: 56th Annual meeting of the Orthopaedic Research Society, New Orleans, LA. Orthopaedic Research Society

29. AOA (2014) Australian Orthopaedic Association National Joint Replacement Registry, Annual report

30. Kohan L, Field C, Kerr D (2013) Minimum 10-year followup of Repicci unicompartmental knee arthroplasty. Bone Jt J 95-B(SUPP 15):228

31. Becker R, Mauer C, Starke C, Brosz M, Zantop T, Lohmann CH, Schulze M (2013) Anteroposterior and rotational stability in fixed and mobile bearing unicondylar knee arthroplasty: a cadaveric study using the robotic force sensor system. Knee Surg Sports Traumatol Arthrosc 21(11):2427-2432

32. Braun S, Minzlaff P, Hollweck R, Wortler K, Imhoff AB (2008) The 5.5-year results of MegaOATS-autologous transfer of the posterior femoral condyle: a case-series study. Arthritis Res Ther 10(3):R68

33. Zhang Q, Zhang Q, Guo W, Liu Z, Cheng L, Zhu G (2015) No need for use of drainage after minimally invasive unicompartmental knee arthroplasty: a prospective randomized, controlled trial. Arch Orthop Trauma Surg 135(5):709-713

34. Shemshaki H, Nourian SM, Nourian N, Dehghani M, Mokhtari M, Mazoochian F (2015) One step closer to sparing total blood loss and transfusion rate in total knee arthroplasty: a meta-analysis of different methods of tranexamic acid administration. Arch Orthop Trauma Surg 135(4):573-588

35. Hourlier H, Reina N, Fennema P (2015) Single dose intravenous tranexamic acid as effective as continuous infusion in primary total knee arthroplasty: a randomised clinical trial. Arch Orthop Trauma Surg 135(4):465-471

36. Liddle AD, Pandit H, Judge A, Murray DW (2015) Patientreported outcomes after total and unicompartmental knee arthroplasty: a study of 14076 matched patients from the National Joint Registry for England and Wales. Bone Jt J 97-B(6):793-801

37. Pearse AJ, Hooper GJ, Rothwell A, Frampton C (2010) Survival and functional outcome after revision of a unicompartmental to a total knee replacement: the New Zealand National Joint Registry. J Bone Jt Surg Br 92(4):508-512

38. Zuiderbaan HA, van der List JP, Khamaisy S, Nawabi DH, Thein R, Ishmael C, Paul S, Pearle AD (2017) Unicompartmental knee arthroplasty versus total knee arthroplasty: which type of artificial joint do patients forget? Knee Surg Sports Traumatol Arthrosc 25(3):681-686 